\title{
Theoretical Exploration of the New Environmental Paradigm Scale in China
}

\author{
Xiaowei Wang ${ }^{1,2}$, Yan Sun ${ }^{1,2^{*}}$ \\ ${ }^{1}$ Key Laboratory of Behavioral Science, Institute of Psychology, Chinese Academy of Sciences, Beijing, 100101, China \\ ${ }^{2}$ Department of Psychology, University of Chinese Academy of Sciences, Beijing, 100049, China
}

\begin{abstract}
The new environmental paradigm (NEP) scale is a widely used instrument to measure human concern for the environment. Since its introduction in China in 2003, Chinese scholars have begun to effectively validate and evaluate its reliability, validity, dimensionality, and applicability in the country. They have made corresponding revisions and adjustments to develop an environmental concern measurement tool with Chinese characteristics. Based on the revised version of the NEP scale's Chinese translation, this paper carries out a comprehensive review of the version revision, validation and evaluation, and practical application. This provides a theoretical basis for developing an environmental concern scale applicable to Chinese characteristics and is of great significance for developing the Chinese version of the NEP scale.
\end{abstract}

\section{Introduction}

In today's increasingly prominent global ecological crisis, environmental issues have become a common survival challenge for people worldwide. Understanding human beings' cognitive belief in the sustainability of natural ecology ${ }^{[1]}$ plays a vital role in protecting the earth's ecological environment. Dunlap and Liere first proposed the new environmental paradigm scale (NEP) in 1978 to measure human-environmental concerns ${ }^{[2]}$. As scholars in various countries debated about the scale and new ecological issues emerged, Dunlap et al. revised the old version of the NEP scale in $2000^{[3]}$ was shown in Table 1 to better test the structure and unity of humans' ecological worldviews and the relationships among a range of specific environmental attitudes, beliefs, and behaviors.

Table 1. The items of revised 00 of the NEP scale.

\begin{tabular}{|c|c|}
\hline Code & Scale Items \\
\hline NEP 1 & $\begin{array}{l}\text { We are approaching the limit of the number of } \\
\text { people the earth can support. }\end{array}$ \\
\hline NEP 2 & $\begin{array}{l}\text { Humans have the right to modify the natural } \\
\text { environment to suit their needs. }\end{array}$ \\
\hline NEP 3 & $\begin{array}{l}\text { When humans interfere with nature it often } \\
\text { produces disastrous consequences. }\end{array}$ \\
\hline NEP 4 & $\begin{array}{l}\text { Human ingenuity will insure that we do NOT make } \\
\text { the earth unlivable. }\end{array}$ \\
\hline NEP 5 & Humans are severely abusing the environment. \\
\hline NEP 6 & $\begin{array}{l}\text { The earth has plenty of natural resources if we just } \\
\text { learn how to develop them. }\end{array}$ \\
\hline NEP 7 & $\begin{array}{l}\text { Plants and animals have as much right as humans } \\
\text { to exist. }\end{array}$ \\
\hline NEP 8 & $\begin{array}{l}\text { The balance of nature is strong enough to cope } \\
\text { with the impacts of modern industrial nations. }\end{array}$ \\
\hline NEP 9 & $\begin{array}{l}\text { Despite our special abilities humans are still } \\
\text { subject to the laws of nature. }\end{array}$ \\
\hline NEP 10 & $\begin{array}{l}\text { The so-called "ecological crisis" facing humankind } \\
\text { has been greatly exaggerated. }\end{array}$ \\
\hline
\end{tabular}

\begin{tabular}{|c|c|}
\hline NEP 11 & $\begin{array}{l}\text { The earth is like a spaceship with very limited } \\
\text { room and resources. }\end{array}$ \\
\hline NEP 12 & Humans were meant to rule over the rest of nature. \\
\hline NEP 13 & $\begin{array}{l}\text { The balance of nature is very delicate and easily } \\
\text { upset. }\end{array}$ \\
\hline NEP 14 & $\begin{array}{l}\text { Humans will eventually learn enough about how } \\
\text { nature works to be able to control it. }\end{array}$ \\
\hline NEP 15 & $\begin{array}{l}\text { If things continue on their present course, we will } \\
\text { soon experience a major ecological catastrophe. }\end{array}$ \\
\hline
\end{tabular}

Due to the strong global promotion value of the NEP scale $^{[1,5]}$, Chinese scholars paved the way to explore the NEP scale locally since it was first cited in a comprehensive social survey in urban China in 2003 by Da Yong ${ }^{[4]}$.

\section{Versions and revisions}

Lu Chuntian (2003) used the revised NEP scale for the first time in a comprehensive social survey in China. This research adopted 15 items of the original scale as they are (hereafter referred to as Version 00 of the NEP scale) except for some rhetorical changes in translation ${ }^{[4]}$. However, Hong argued that, when applying Version 00 of the NEP scale in China, both items 4 and 14 should be deleted, and only the remaining 13 items should be retained. Thus, the revision produced a NEP scale that is more applicable to urban areas in China (hereafter referred to as Version 03 of the NEP scale) ${ }^{[4]}$. Xiao Chenyang et al. (2007) found that the design with alternating positive and negative wording of the items in Version 00 of the NEP scale would likely seriously interfere with its practical application in China today; therefore, five of the items, namely $2,4,6,12$, and 14 , were removed. The remaining 10 items were reassembled to form a new scale (hereafter referred to as Version 07 of the NEP scale $)^{[6]}$. Wu et al.

\footnotetext{
* Corresponding author: suny@psych.ac.cn
} 
(2011, 2012) retranslated and back-translated Version 00 of the NEP scale, redefined the Chinese translation and wording of the question categories after a two-way intertranslation, and used the Likert 5-point scoring method to score the 15 questions in the scale (hereafter referred to as Version 12 of the NEP scale $)^{[7,8]}$. Wu (2012) conducted a preliminary revision of the NEP scale's student version based on Version 00 of the NEP scale and Version 12 of the NEP scale ${ }^{[9]}$. Hong Dayong et al. (2014) scientifically evaluated Version 00 and Version 07 of the scale again by using CGSS 2010 data covering both urban and rural China $^{[10]}$ and defined the Chinese new environmental paradigm (CNEP) scale by further validating that Version 07 of the NEP scale was more adaptive than the Version $00^{[10]}$. Wu Lingqiong (2017) revised the 2012 elementary school students' version of the NEP scale concerning Versions 03 and 11, thereby forming the elementary school students' and the college students' versions of the scale. Wu Ling qiong, thus, provided a valid measurement tool for studying the relationship between environmental attitudes and environmental behaviors of elementary school students and higher education students' institutions in China ${ }^{[11]}$. The CNEP scale would cause inconvenience in the international comparison of future measurement results. Fan Yechao (2017) found during the validation process that Version 00 of the NEP scale after unifying the wording directions (hereafter referred to as Version 17 of the NEP scale) could still be the best tool for measuring environmental concern among college students ${ }^{[12]}$. Fan Yechao and Xiao Chenyang believe that (2019) the option of "unable to select" should be removed from the questionnaire design of the CNEP scale to avoid an increase in the proportion of missing data in various items in the $\mathrm{CNEP}^{[13]}$

\section{Validation and evaluation}

\subsection{Validation of reliability and validity}

Scholars in China and other countries have widely recognized the reliability and validity of the NEP scale ${ }^{[1]}$. Scholars have also been continuously validating it in terms of whether it has the same high reliability and validity in China.

In the process of validating Version 00 of the NEP scale, Hong found that its reliability and validity were not very good if the entire scale was adopted as it is, to measure the Chinese public's concern for the environment. The reliability and validity of Version 03 of the NEP scale, with the deletion of items 4 and 14, were significantly improved $^{[4]}$. Version 00 of the NEP scale was not well applied in rural areas of China. However, the NEP scale's rural version, with Only 3, 5, 10, 12, 13, and 15 items retained, had better reliability and validity ${ }^{[14]}$. The predictive validity of Version 00 of the NEP scale was not satisfactory after unifying the wording directions. Nevertheless, the validity was expected to be further improved after splitting it into five sub scales separately ${ }^{[12]}$. Version 07 of the NEP scale, called the CNEP scale, had better reliability and validity levels for measuring Chinese urban and rural residents' environmental concerns compared to Version 00 of the NEP scale ${ }^{[6,10]}$. Version 12 of the NEP scale also has higher levels of reliability and validity ${ }^{[8]}$. While both the elementary student and the college student versions of the NEP have good reliability, their validity needs to be specifically determined and analyzed $^{[11]}$.

\subsection{Validation of dimensionality}

The revised NEP scale measures five interrelated dimensions of environmental concern: "balance of nature," "anthropocentrism," "human exceptionalism," "ecological crisis," and "limits to growth." However, there is no consensus or uniform conclusion among scholars on its dimensionality ${ }^{[5]}$. Chen yang et al. proposed to use the Confirmatory Factor Analysis (CFA) method ${ }^{[6]}$. They found that the CGSS2003 data did not support the hypothesis that Version 00 of the scale was onedimensional or five-dimensional by analyzing three models $^{[7]}$. The environmental concern measurement model constructed by $\mathrm{Lu}$ et al. based on the CGSS2003 data concluded that it is more appropriate to construct environmental concern into four dimensions ${ }^{[15]}$. Wu et al. divided Version 12 of the NEP scale into two dimensions, such as "new ecological paradigm," and further validated its rationality ${ }^{[11]}$. Based on the CGSS2010 data which was shown in Table 2, Hong, D (2014) validated Version 00 and Version 07 of the NEP scale. He found that Version 00 of the NEP scale was neither five-dimensional nor unidimensional when applied in China. The unidimensional hypothesis support for Version 07 of the NEP scale was effectively supported in urban samples but neither effectively supported nor completely rejected in rural samples ${ }^{[10]}$. Chen et al. held that dimensionality is mainly influenced by the changing conditions of life and the social environment in which the researched subjects live under their cultural beliefs and socioeconomic conditions ${ }^{[5]}$. Wu Lingqiong held that the idea of a threedimensional theoretical model of the student version of the NEP scale requires further discussion ${ }^{[11]}$. After unifying the wording directions, Fan (2017) concluded from validation that the unidimensional model of Version 00 of the NEP scale fits the data more effectively than the fivedimensional model ${ }^{[12]}$. Wen (2019), after deleting items 6 , 7 , and 9 based on Version 00 of the NEP, found that the two-dimensional NEP scale consisting of the remaining 12 items could effectively detect ecological awareness of ecological migrants ${ }^{[16]}$. Liu Jingjia (2020), in a survey of visitors at Pudacuo National Park, similarly divided Version 00 of the NEP scale into two dimensions ${ }^{[17]}$.

Table 2. Survey results of validated Version 00 of the NEP scale in China.

\begin{tabular}{cccccccc}
\hline $\begin{array}{c}\text { 00 of } \\
\text { NEP } \\
\text { scale }\end{array}$ & \multicolumn{2}{c}{$\begin{array}{c}\text { Total } \\
\text { sample } \\
\mathrm{n}=3480\end{array}$} & \multicolumn{2}{c}{$\begin{array}{c}\text { City } \\
\text { sample } \\
\mathrm{n}=2264\end{array}$} & \multicolumn{2}{c}{$\begin{array}{c}\text { Rural } \\
\text { sample } \\
\mathrm{n}=1216\end{array}$} & $\begin{array}{c}\text { Res. } \\
\text { Coe. }{ }^{1}\end{array}$ \\
\hline NEP 1 & 3.59 & 0.96 & 3.66 & 0.96 & 3.45 & 0.95 & 0.90 \\
NEP 2 & 3.17 & 1.19 & 3.28 & 1.21 & 2.98 & 1.13 & 1.46 \\
NEP 3 & 3.94 & 0.89 & 4.04 & 0.86 & 3.75 & 0.91 & 0.97 \\
NEP 4 & 2.38 & 0.98 & 2.38 & 1.01 & 2.36 & 0.94 & 0.37 \\
NEP 5 & 3.85 & 0.98 & 3.96 & 0.92 & 3.65 & 1.06 & 1.12 \\
NEP 6 & 2.92 & 1.17 & 3.01 & 1.21 & 2.75 & 1.09 & 1.21 \\
NEP 7 & 4.07 & 0.90 & 4.15 & 0.86 & 3.93 & 0.95 & 0.94 \\
\hline
\end{tabular}




\begin{tabular}{cccccccc}
\hline NEP 8 & 3.40 & 1.04 & 3.53 & 1.06 & 3.16 & 0.97 & 1.44 \\
NEP 9 & 3.93 & 0.90 & 4.02 & 0.89 & 3.75 & 0.90 & 0.93 \\
NEP 10 & 3.40 & 1.03 & 3.53 & 1.03 & 3.17 & 0.98 & 1.33 \\
NEP 11 & 3.74 & 0.98 & 3.86 & 0.97 & 3.51 & 0.98 & 1.22 \\
NEP 12 & 3.33 & 1.16 & 3.45 & 1.17 & 3.11 & 1.10 & 1.55 \\
NEP 13 & 3.76 & 0.95 & 3.87 & 0.94 & 3.56 & 0.94 & 1.13 \\
NEP 14 & 2.80 & 1.10 & 2.83 & 1.15 & 2.74 & 1.01 & 0.79 \\
NEP 15 & 3.69 & 1.02 & 3.81 & 1.01 & 3.46 & 1.00 & 1.31 \\
1 & \multicolumn{7}{l}{ Res. Coe. $=$ Resolution Coefficient. }
\end{tabular}

\subsection{Applicability assessment}

Scholars have investigated and analyzed the applicability of different versions of the scale currently available in China in different geographic areas and audiences. Copying the contents of Version 00 of the NEP scale is more problematic when investigating the application assessment of Version 00 of the scale in rural areas of western China $^{[14]}$. Version 00 of the NEP scale was found to be internally inconsistent for different types of populations in the mountainous southwestern regions ${ }^{[18]}$ and not fully applicable to measuring the environmental attitudes of Chinese primary school students ${ }^{[9]}$ or measuring the ecological awareness of migrants in ecological migration areas ${ }^{[16]}$. If Version 00 of the NEP scale is reasonably modified, it can be largely applicable to measuring ecological concern in the field of tourism in China $^{[19]}$. Version 07 of the NEP scale has empirical evidence regarding the applicability for urban Chinese residents $^{[20]}$, but is not fully applicable to rural China ${ }^{[14]}$.

\section{Conclusion}

The above discussion shows that the NEP scale has a certain degree of applicability in China as a useful tool for measuring people's environmental awareness, attitudes, and concerns. Further, it guides the development of effective environmental protection policies and the adoption of effective environmental protection measures. Simultaneously, the NEP scale has also been found to be "unsuitable" to China. The author makes the following comments.

1. Scholars in China have continued to conduct indepth research on the attributes of the NEP scale. However, the NEP scale has not yet been revised with Chinese characteristics to suit local conditions. In particular, for China, which has 129 dialects, the choice of wording and the selection of items need to be explored and revised according to different cultural contexts and contemporary backgrounds.

2. In the current social context, there is still further scope for applying the NEP scale. Scientific selection of applicable versions, measurement methods, and tests are essential.

3. Although some scholars have chosen the NEP scale as a measurement tool, they have not systematically and effectively validated its measurement quality in their studies. There are limitations in the reliability of the relevant research theories. The examination of the reliability, validity, and dimensionality of the NEP scales is still a major concern for future research work.

4. The NEP scale should continue to be widely applied to different populations, regions, and fields in China. Its applicability is still limited at present. However, it is believed that through the joint efforts of scholars in China and other countries, a high-quality environmental concern measurement tool that meets China's national conditions and is comparable to international ones will be developed.

\section{Funding}

This work was supported by the National Social Science Fund of China [No.18BGL180].

\section{References}

1. Dunlap, Riley E. The New Environmental Paradigm Scale: From Marginality to Worldwide Use. The Journal of Environmental Education., 40 (1): 3 18 (2008).

2. Dunlap, R. E., Van Liere, K. D. The "New Environmental Paradigm": A proposed measuring instrument and preliminary results. The Journal of Environmental Education., 9 (4): 10 19 (1978).

3. Dunlap, R. E., Van Liere, K. D., Mertig, A. G., Jones, R. E. Measuring endorsement of the New Ecological Paradigm: A Revised NEP Scale. Journal of Social Issues., 56, 425 442 (2000).

4. Hong Da Yong. Measurement of Environmental Concern: Evaluation of the NEP Scale in China.Society., 26: 71 92 (2006).

5. CHEN Yue-zhen, XIE Hong-bin, HUANG Jin-huo. The New Ecological Paradigm and It Practical Application. Journal of Shanxi Normal University Natural Science Edition., 1(3):112 119 (2014).

6. Xiao Chen Yang, Hong Da Yong. Reanalysis of the application of NEP in China. Social Science Journal., 1(168): 55 63 (2007).

7. Wu, J.P., Zi, F., Wang, G.X., Yang, Z.H., Liu, X.W., Jiang, J.H., et al. A research on the relationship between ecological unconscious and Environmental concern of Chinese Urban Residents. Paper presented at the Ninth Biennial Conference of Asian Association of Social Psychology, Kunming, China (2011, July).

8. WU Jian-ping, ZI Fei, LIU Xian-wei., et al. Measurement of New Ecological Paradigm: Revision and Application of NEP Scale in China. Journal of Beijing Forestry University (Social Sciences)., 12(4): 8 13 (2012).

9. $\mathrm{Wu}$ Lingqiong. Exploring the new ecological paradigm scale for gauging children's enviromental attitudes in China. The Journal of Environmental Education., 43 (2): 107 120 (2012).

10. Hong Dayong, Fan Yechao, Chenyang. Re-examining the Measurement Quality of the Chinese New Environmental Paradigm (CNEP) Scale: An analysis based on the CGSS 2010 data., 4: 49 75 (2014).

11. WU Lingqiong, ZHU Yan. Revision of New Ecological Paradigm (NEP) Scale in Urban Student Groups in China and its Reliability and Validity Test. 
Journal of Nanjing Tech University (Social Science Edition)., 2(16): 53 61 (2017).

12. FAN Yechao. Re-evaluation of Project Wording Direction and the Application of NEP Scale in China. Journal of Nanjing University of Technology (Natural Science Edition)., 6(12): 62 69 (2017).

13. FAN Yechao, XIAO Chenyang. On Techniques to Handle Item Missing Data and Their Efficiency Assessment: An Case Study on CNEP Scale's Application. Journal of Nanjing University of Technology (Natural Science Edition)., 6:64 79 (2019).

14. WANG Ling, FU Shao-ping. Application of the NEP scale in rural areas of western China-A case study in northern village of Shanxi province. Guangdong Agricultural Sciences., 19: 210 212 (2011).

15. Lu Chuntian, Hong Dayong. Constructing a Model for Measuring Environmental Concern: Based on the 2003-CGSS Dataset. Society., 1(36): 35 52 (2003).

16. Ou Yaowen, Dong Mei. Evaluation on the application of new ecological paradigm scale in Ningxia ecological migration area. Journal of Agricultural Sciences., 3(40): 8 14 (2019).

17. LIU Jingjia. Research on environmental education demands of national parks based on NEP scale-A case study of Putatso National Park. Forestry and Ecological Sciences., 35(3): 343 352 (2020).

18. Liu Jing, Zhiyun, Ouyang, Hong Miao. Environment Attitude of Stakeholders and Their Perception Regarding Protected Area-community Conflicts: A Case Study in China. Journal of Environmental Management 91 (2010).

19. LIU Ru-fei. Selective Marketing for Sustainable Development of Tourism Based on the Analysis of Environmental Behavior- A Case Study of Jiuzhaigou. Human Geography., 6(116): 114 119 (2010).

20. GONG Wen-juan. A Gender Comparison on the Environment-friendly Behaviors of Contemporary Urban Residents. Journal of China University of Geosciences (Social Sciences Edition)., 8(6): 37 42 (2008). 